\title{
Importance of coastal Marine Protected Areas for the conservation of pelagic seabirds: The case of Vulnerable yelkouan shearwaters in the Mediterranean Sea
}

\author{
Clara Péron ${ }^{\mathrm{a}, *}$, David Grémillet ${ }^{\mathrm{a}, \mathrm{b}}$, Aurélien Prudor ${ }^{\mathrm{a}}$, Emeline Pettex ${ }^{\mathrm{c}}$, Claire Saraux ${ }^{\mathrm{d}}$ \\ Andrea Soriano-Redondo ${ }^{a}$, Matthieu Authier ${ }^{a}$, Jérôme Fort ${ }^{\mathrm{e}}$
}

\footnotetext{
a CEFE-CNRS, UMR5175, 1919 route de Mende, 34293 Montpellier, France

${ }^{\mathrm{b}}$ FitzPatrick Institute, DST-NRF Centre of Excellence at the University of Cape Town, Rondebosch 7701, South Africa

' Observatoire PELAGIS, Systèmes d'Observation pour la Conservation des Mammifères et des Oiseaux Marins, UMS 3462, Université de La Rochelle-CNRS, Pôle Analytique, 5 allées de l'Océan, 17000 La Rochelle, France

d UMR 212 EME, IFREMER (Institut Français de Recherche pour l'Exploitation de la Mer), Sète, France

${ }^{e}$ Department of Bioscience, Aarhus University, Frederiksborgvej 399, 4000 Roskilde, Denmark
}

\author{
*: Corresponding author : Clara Péron, tel.: +33 467613311 ; email addresses : clara.peron@cefe.cnrs.fr ; \\ clara.peron22@gmail.com
}

\begin{abstract}
:
Marine Protected Areas (MPAs) are being established across all marine regions but their validity for the conservation of highly mobile marine vertebrates has been questioned. We tested the hypothesis that French coastal MPAs primarily designed for coastal and benthic biota are also beneficial for the conservation of a pelagic seabird, the Vulnerable yelkouan shearwater (Puffinus yelkouan), an endemic species to the Mediterranean Sea. We used a vast spectrum of electronic devices (GPS, temperature-depth-recorders, satellite transmitters and geolocators) and stable isotopic analyses to study the year-round movements and the trophic status of yelkouan shearwaters from the Hyères archipelago (France). In addition we conducted large-scale ship and aircrafts observation surveys to investigate spatio-temporal density patterns of shearwaters (genus Puffinus) in the western Mediterranean Sea. This extensive investigation permitted the first comprehensive study of the at-sea ecology of yelkouan shearwaters showing strikingly coastal habits, partial migration, unsuspected diving capabilities (max dive depth of $30 \mathrm{~m}$ ), and a broad diet ranging from zooplankton to small pelagic fish. Importantly, $31 \%$ of yelkouan shearwaters GPS positions associated with foraging, $38 \%$ of diving positions, and $27 \%$ of resting positions were within the three French MPAs during the breeding season. These high scores confirmed by year-round distribution derived from GLS, PTTs, atsea and aerial observations, validated our hypothesis of the major importance of coastal MPAs for the conservation of yelkouan shearwater. Our case-study is therefore a major contribution to research efforts aiming at linking the spatial ecology of highly mobile marine vertebrates with effective conservation of marine biodiversity.
\end{abstract}

Keywords: Aerial surveys ; At-sea observations ; Biotelemetry ; Conservation biogeography ; Spatial planning ; Stable isotope analysis 


\section{Introduction}

The Mediterranean basin is a biodiversity hotspot, and this designation is largely based upon high levels of endemism within terrestrial ecosystems (Myers et al., 2000). For geologic and climatic reasons, the fauna and flora of the Mediterranean Sea show lower levels of endemism than terrestrial biota (Fredj et al., 1992). Although the Mediterranean Sea only represents $0.82 \%$ of the world ocean area and $0.3 \%$ of its volume, its species richness nonetheless corresponds to $4-18 \%$ of all marine species, depending on the phylum taken into consideration (Lejeusne et al., 2010). Endemism within Mediterranean marine communities reaches $28 \%$, and considering major threats to related ecosystems, Blondel and colleagues (2010) argued that the hotspot concept should equally apply to Mediterranean marine biota. Indeed, global anthropogenic changes are impacting many Mediterranean endemic marine species, in particular seabirds (Coll et al., 2012). Four endemic seabird species sensu stricto inhabit the Mediterranean Sea: Audouin"s gull (Larus audouinit), Scopoli"s shearwater (Calonectris diomedea), yelkouan and balearic shearwaters (respectively Puffinus yelkouan and Puffinus mauretanicus). All of these species have been subjected to human impacts throughout the Holocene (Zotier et al., 2003). Historically, the first human stresses upon seabird populations has probably been harvesting for food, which continues until today on some Mediterranean islands (Borg et al., 2010). Long-lasting persecutions resulted in seabird populations which are particularly sensitive to disturbance compared to relatives in more recently-colonised regions of the world (Blondel et al., 2010). Second, humans have also been introducing alien species such as mice, rats and cats on seabird insular breeding sites since historical times (Ruffino et al., 2009). These predators of seabird eggs, nestlings and adults are, together with destruction of breeding habitats, the major recurrent threat to Mediterranean breeding seabirds (Zotier et al., 2003, Ruffino et al., 2009). Third, seabirds are also subjected to series of threats at sea, the most serious being probably accidental bycatch by fisheries (Arcos et al., 2008 ; Laneri et al., 2010), followed by food shortage resulting from competition with fisheries (Cury et al., 2011), the impact of diverse pollutions (Sanpera et al., 2007) and disturbance by offshore infrastructures (e.g. wind turbines) (Garthe and Hüppop 2004). Finally, seabirds might be impacted indirectly by climate change, for instance via extreme weather events (Grémillet and Boulinier 2009), or changing phenologies causing the mismatch of predators and their prey in space and/or time (Grémillet et al., 2008). Threats to seabirds are classically much harder to deal with at sea than on land, for obvious logistical reasons, and also by lack of knowledge about their at-sea ecology. In the Mediterranean Sea, species such as the Audouin"s gull have been studied extensively (Oro et al., 2004), and conservation programmes have drawn a clear picture of necessary management (Arcos et al., 2008). Further studies have also recently been conducted, or are underway, to identify key marine habitats for the conservation of the Critically endangered balearic shearwaters (Louzao et al., 2006 ; Louzao et al., 2012 ; Guilford et al., 2012). With respect to the yelkouan shearwater, hardly any information were available until very recently. Thanks to the use of miniaturised geolocators, first insights were gathered about the inter-breeding movements of yelkouan shearwaters breeding in France (Militão et al. 2012) and Malta (Raine et al., 2013). However, due to the low positioning accuracy inherent to geolocators (Phillips et al., 2004), these studies only broadly defined inter-breeding areas, and they did not inform about movements, habitat-use and fine-scale distribution of birds during the breeding period. Such lack of information is unfortunate, since this species is listed as Vulnerable since 2012 (BirdLife International 2012) and clearly deserves improved conservation measures on a year-round basis. Indeed, mark-recapture studies conducted in France and Malta strongly suggested low adult survival probabilities causing steady population declines over the past four decades (Oppel et al., 2011). This is calling for immediate action at breeding sites, where eradication or control of alien species is underway (Capizzi et al., 2010), but also for identification and protection of marine habitats critical for the conservation of this species. 
Our objective was therefore to perform the first detailed study of the at-sea ecology of yelkouan shearwaters in the western Mediterranean Sea. To this aim, we used a vast spectrum of biotelemetry techniques in combination with direct observations conducted both from a research vessel and from airplanes as well as stable isotopic analyses to provide the most complete picture of adult yelkouan shearwaters marine ecology across the year cycle. Although we tracked shearwaters during the inter-breeding period across the Mediterranean Sea and into the Black Sea, our study primarily focused on the Western Mediterranean. This area includes breeding colonies, and a series of distinct Marine Protected Areas (MPAs). We tested the hypothesis that existing MPAs designed without prior knowledge of yelkouan shearwater habitat-use, include critical yelkouan shearwater marine habitats across the year, and are therefore suitable for the conservation of this Vulnerable species.

\section{Materials and Methods}

Distribution and movements of seabirds at sea can be studied using three independent methods: (1) biotelemetry, based on positions acquired by electronic devices (2) at-sea observations conducted either from the coast or from ships and (3) aerial surveys conducted from aircrafts. In this study, we combined the three methods to yield the most comprehensive picture of yelkouan shearwater at-sea distribution. Additional information on yelkouan shearwaters at-sea ecology was also obtained using depth recorders and isotopic analyses, to gain knowledge about their diving behaviour and trophic status.

\subsection{Species biology and study sites}

Our study focused on the yelkouan shearwater, a medium-size shearwater species (30-38 $\mathrm{cm}$ long, with a 76-89 $\mathrm{cm}$ wingspan) endemic to the Mediterranean basin, which breeds on mostly uninhabited islands from France to Turkey (Bourgeois 2011). Global population estimates are highly uncertain (7 311-53 785 breeding pairs), including both demographic monitoring and at-sea counts (Bourgeois 2011). Breeding distribution and population sizes remain partly unknown because this nocturnal burrow-nesting species is very cryptic on land; birds breed in deep burrows located on steep coastal cliffs (Bourgeois 2011). Our study was carried out in the western Mediterranean basin (Fig. 1, breeding colonies are identified with black dots). The biotelemetry study was conducted from the Hyères archipelago (Porquerolles, Port-Cros, Bagaud and Levant Is.), where 95\% of the French Yelkouan shearwater population breed (Fig. 1). The total population estimate for the Hyères archipelago varies between 596 and 1007 breeding pairs (Bourgeois 2011). Between 143 and 235 pairs of yelkouan shearwaters breed on Port-Cros and 66-121 on Porquerolles islands (Bourgeois 2011). Black rats (Rattus rattus) and feral cats (Felis catus) have proved to prey on eggs, chicks and adults (Bonnaud et al., 2007) on breeding colonies. Whereas feral cats are no longer present in Port-Cros, they still cause damaged in Porquerolles Is..

Yelkouan shearwaters first return to breeding sites in late October to display and defend their burrow (Zotier 1997). Egg-laying takes place from mid-March to early April, hatching in May and fledging in July. Both adults incubate the single egg and rear the chick (Zotier 1997). Approximately five days after hatching, the chick is left alone in the burrow and fed by its parents at night for $\sim 89$ days (Bourgeois 2011). Adults leave the colony after chick fledging in July (Bourgeois 2011). 


\subsection{French MPAs in the Mediterranean Sea}

Three large MPAs are in place along the French Mediterranean coast: the Parc National de Port Cros, the oldest French marine National Park, established in1963 in the Hyères archipelago (Fig. 1), the newly-established Parc National des Calanques off Marseille (2012) and the Parc Naturel Marin du Golfe du Lion (2011). These three MPAs cover respectively $152 \mathrm{~km}^{2}, 1413 \mathrm{~km}^{2}$ and $4019 \mathrm{~km}^{2}$ (Fig. 1). Marine extension of National Parks is divided into a core and a peripheral area, protection measures being more ambitious within core areas (29 km $\mathrm{km}^{2}$ and $435 \mathrm{~km}^{2}$ for the Parc National de Port-Cros and Calanques, respectively). The core area of the Parc National de Port-Cros corresponds to a $600 \mathrm{~m}$ band around Porquerolles and Port-Cros islands (Fig. 1). Shearwaters movements and behaviours were thus confronted to MPAs to assess their spatial overlap. Spatial data were projected to Lambert 93 coordinates system in ArcGIS 9.3.1.

\subsection{Individual tracking using biotelemetry}

Our biotelemetry study was conducted from Port-Cros $\left(43^{\circ} 00^{\prime \prime} \mathrm{N}, 6^{\circ} 23^{\prime \prime} \mathrm{E}\right)$ and Porquerolles $\left(43^{\circ} 00^{\prime} \mathrm{N}, 6^{\circ} 12^{\prime \prime} \mathrm{E}\right)$, within the Parc National de Port-Cros (Fig. 1). We fitted/recovered biotelemetry devices to breeding adults in May-June 2011 and 2012, during the chick-rearing period. Birds were caught at night at the entrance of their nesting burrows, as they were leaving towards/returning from the sea. Handling was kept minimal ( $<10$ minutes) and performed in silence to minimize stress. Three types of electronic devices were used to determine bird movements and distribution across the year cycle:

(1) GPS recorders, miniaturized and waterproof (Earth\&Ocean Technologies, Kiel, Germany; $12.5 \mathrm{~g} ; 47 \times 23 \times 12 \mathrm{~mm}$ ) were deployed on 29 adults rearing a chick (13 in 2011 and 16 in 2012). They were programmed to store a position every three minutes with a positioning error $<30 \mathrm{~m}$. The logger was attached to feathers of the lower back with Tesa ${ }^{\circledR}$ tape, for one to five days. Due to device loss or failures, data were collected for seven and 13 birds in 2011 and 2012, respectively. Of those data sets, seven and five were complete, respectively. The other devices had discontinuous signals or stopped storing data as the birds were on their way back to the nest. We excluded incomplete tracks for calculation of trip descriptive parameters (duration, range, distance travelled). Total travelled distance and maximal range have thus been under-estimated in 2012 due to the exclusion of incomplete tracks.

Among shearwaters equipped and recaptured with GPS, 10 (three in 2011 and seven in 2012) were also equipped with a temperature-depth-recorder (TDR, G5, CEFAS Technologies, Lowestoft, UK; $2.7 \mathrm{~g} ; 30 \mathrm{~mm}$ length, $7 \mathrm{~mm}$ diameter) taped to the underside of central rectrices. TDRs were set to record hydrostatic pressure every two seconds. The combined mass of GPS and TDR represented 3.5\% of the average birds"body mass.

Diving dates were extracted from TDR data using an automatic procedure which identified when the pressure differences between two successive records was higher than $1 \mathrm{hPa}$ (i.e. $\delta$ depth $<-1 \mathrm{~m})$. We then defined a diving location where at least one dive was recorded between two successive GPS locations.

(2) Platform Terminal Transmitters (PTTs, Microwave Telemetry, USA; $9.5 \mathrm{~g} ; 38 \times 17 \times 12 \mathrm{~mm}$ ) were deployed on one failed breeder in 2011 and 5 breeders in 2012, at the end of the chick rearing period (mid-June) to track their post-breeding movements (details in Appendix Table A.1). PTTs were taped to the back feathers of adults. They represented $2.2 \%$ of the average birds" body mass. PTTs were solar panelled with a duty cycle of $12 \mathrm{H} \mathrm{ON} / 48 \mathrm{H}$ OFF. They usually provided 6-10 positional fixes every two days with spatial accuracy varying 
depending on fixes (from $<150 \mathrm{~m}$ to $>1 \mathrm{~km}$ ). Satellite data were acquired in real-time until the devices stopped transmitting (due to device failure, device detachment or bird death).

(3) Global Location Sensors (GLS, Biotrack, UK; MK19, $2.5 \mathrm{~g}, 16 \times 17 \times 6 \mathrm{~mm}$ ) were attached to a plastic foot ring with a cable tie. The overall package represented $0.6 \%$ of the average birds" body mass. Twenty-five breeding adults were equipped with GLS in 2011 in Port-Cros ( $n=15$ individuals) and Porquerolles ( $n=10$ individuals). Nineteen GLS (76\%) were recovered in 2012 or 2013 and 15 successfully downloaded. Light data were analysed to estimate the position of the birds twice per day (Wilson et al., 1992) using the software TransEdit and BirdTracker provided by the British Antarctic Survey (see details in Appendix A.1). We filtered out locations around the equinox (10 days) and applied a speed filter ( $<80 \mathrm{~km} . \mathrm{h}-1)$ to delete erroneous locations. Inter-breeding distribution was estimated using Kernel density estimation with a smoothing factor set to $1^{\circ}$ in accordance with the intrinsic low accuracy of GLS.

\subsection{Bayesian state-space model for behavioural mode inferences}

Discrete behavioural modes were inferred from GPS movement data using a state-space model adapted from the triple-switch model in Morales et al. (2004). This method allows estimation of the sequence of states in animal tracking data where behaviour itself is not directly observable, while accounting for measurement error. Given the high accuracy of GPS fixes, we ignored measurement error. We hypothesized three ,hidden" behavioural modes: resting (small turning angle variance, small step length), foraging (large turning angle variance, intermediate step length), and travelling (small turning angle variance, large step length). Details on state-space models methodology can be found in Appendix (A.2). We used posterior state probabilities to estimate activity budget and map bird behaviour.

\subsection{Vessel-based survey}

A vessel-based seabird survey was conducted in the Gulf of Lion between the 29th June and the $19^{\text {th }}$ July 2012 on board RV N/O L"Europe, during a yearly research cruise aiming at assessing stocks of small pelagic fish in the Gulf of Lion. One observer recorded bird sightings along strip transects while the ship was en route at ca. 8 knots, from a height of 7 $\mathrm{m}$, over a $120^{\circ}$ radius centred on the bow, and within $300 \mathrm{~m}$ bandwidth. This protocol was adapted from Tasker et al. (1984) and Camphuysen (2004) to comply with logistic constraints dictated by vessel configuration and the fact that only one observer was allowed onboard. Environmental conditions (Beaufort sea state, glare, cloud coverage and subjective assessment of sighting conditions) were recorded at the beginning of each transect and when a change occurred in the sighting conditions. Counts were stopped during trawling activity and for 30 more minutes after trawling operations to minimize the effect of bird attraction. The total observation effort was $939 \mathrm{~km}$ of transect lines (Appendix, Fig. A.1), which corresponds to $63 \mathrm{~h}$ of observation. Since yelkouan and balearic shearwaters are difficult to distinguish at sea, we pooled observations of both species to a group named Puffinus sp. This term refers to yelkouan and Balearic shearwaters since other Puffinus sp. are very rare in the Mediterranean Sea. We accounted for spatial variations in observation effort (Appendix, Fig. A.1) by calculating the number of kilometres travelled in each cell i of a regular grid $\left(0.05^{\circ} \times 0.05^{\circ}\right)$ and bird density (no.birds. $\left.\mathrm{km}^{-1}\right)$ as the number of Puffinus sp. sightings in cell $\mathrm{i}$ divided by the observation effort in this cell. 


\subsection{Aerial surveys}

Aerial surveys were conducted in winter between the $1^{\text {st }}$ December 2011 and the $27^{\text {th }}$ January 2012 (12 $157 \mathrm{~km}, 73$ hours on effort) and in spring between the $21^{\text {th }}$ May and $2^{\text {sd }}$ June 2012 (9 $839 \mathrm{~km}, 59$ hours on effort). The survey area encompassed the French Exclusive Economic Zone (EEZ) and adjacent waters (Fig. 2D). Aerial surveys were conducted after a standard strip transect sampling, assuming that all seabirds were detected within the strip $200 \mathrm{~m}$ wide on both sides of the track (Tasker et al., 1984). A stratified survey design was implemented (see Appendix, Fig. A.2 and A.3). Zigzag transects were designed to maximize flight effort. The aircrafts were high-wing, double-engine Britten Norman 2, equipped with bubble windows in order to observe underneath the plane. Transects were sampled at a ground speed of $167 \mathrm{~km} \cdot \mathrm{h}^{-1}$ and an altitude of $182 \mathrm{~m}$. Two trained observers were transmitting their sightings to the flight leader collecting the data on a laptop computer, using VOR software (designed for aerial survey, see Hammond et al., 2013). Environmental conditions (Beaufort sea state, turbidity, glare, cloud coverage and subjective assessment of sighting conditions) were recorded at the beginning of each transect and when a change occurred in the sighting conditions. Positions were collected every two seconds using a GPS. As for vessel-based survey, yelkouan and balearic shearwaters were gathered in a Puffinus sp. group. Densities of Puffinus species were calculated on a regular grid of $0.1^{\circ} \times 0.1^{\circ}$ to correct for spatial heterogeneity in survey effort (see Appendix, Fig. A.2 and A.3).

\subsection{Trophic status using stable isotope analyses}

Conventional dietary techniques such as stomach content analyses are logistically and ethically not practicable in yelkouan shearwaters and we therefore used stable isotopic analyse to assess their trophic status across the year cycle. We sampled the tips $(1-2 \mathrm{~cm})$ of the first primary feather (P1) and one cover feather in breeding adults handled during biotelemetry fieldwork (May-June 2011 and 2012) at Port-Cros and Porquerolles Is.. A total of 37 and 33 first primary feathers (P1) and 38 and 34 cover feathers were analyzed in 2011 and 2012, respectively. Because feathers are metabolically inert, their isotopic signatures are typical of the time period of feather growth (Bearhop et al., 2002). Though the moulting sequence of the yelkouan shearwater is poorly known, a recent study performed on balearic and yelkouan shearwaters provided evidence that P1 isotopic signature can be used in stable isotope analyses to infer the trophic status of yelkouans during the inter-breeding period (Militão et al., 2012). Recent evidences suggest that cover feathers are replaced along the breeding season and therefore provide information for this specific period $(\mathrm{K}$. Bourgeois, personal communication). Details on feathers preparation and calculations of isotopes abundances can be found in Appendix A.3.

$\delta^{15} \mathrm{~N}$ isotopic values reflect the trophic level while $\delta^{13} \mathrm{C}$ values reflect carbon source, characteristic of the foraging location (Kelly 2000).

Yelkouan shearwaters can occupy different geographic areas during the inter-breeding period where bird diet can vary. We tested for potential differences, by running a hierarchical cluster analysis on $\mathrm{P} 1 \delta^{13} \mathrm{C}$ isotopic values. Geographic region corresponding to each group was then inferred based on annual distribution of the 12 birds tracked with GLS in 2011-2012 (during P1 growth) for which isotopic data were measured in 2012. The trophic level of yelkouan shearwaters ( $\left.T L_{Y S}\right)$ in the Mediterranean Sea during the different seasons was estimated following the equation as described by Weiss et al. (2009) for seabirds:

$T L_{Y S}=3+\left(\delta^{15} N_{Y S}-\Delta d_{\text {feather }}-\delta^{15} N_{\text {Copepods }}\right) / 3.4$ 
Where $\delta^{15} N_{Y S}$ is the nitrogen isotopic ratio, $\Delta d_{\text {feather }}$ is the diet-tissue discrimination factor for feathers (4.4\%o; Hobson and Bond 2012) and $\delta^{15} \mathrm{~N}_{\text {copepods }}$ is the average values measured on copepods (assumed to be at trophic level 2) in the western Mediterranean Sea $(2.8 \%$; Cardona et al., 2012). We assumed a constant trophic enrichment factor of $3.4 \%$ (Post 2002). Trophic level of yelkouan shearwaters spending the non-breeding period in the Black Sea (see results) could not be estimated because no information were available on isotopic values of primary consumers in the part of the Black Sea exploited by these birds.

Since the isotopic signature of a predator is directly linked to the ones of its prey (Kelly 2000), we used the isotopic signatures of three small pelagic fish included in yelkouan shearwater diet (Bourgeois et al., 2011) to interpret our results on shearwater isotopic signatures. Fish isotopic signatures were derived from muscles sampled on European pilchard (Sardina pilchardus, $\mathrm{n}=30$ ), European anchovy (Engraulis encrasicholus, $\mathrm{n}=44$ ) and European sprat (Sprattus sprattus, $\mathrm{n}=33$ ) during scientific surveys conducted in the Gulf of Lion by IFREMER (MEDITS, international campaign of demersal trawling and PELMED, acoustic and trawling campaign on small pelagic fish) in June and July 2011 onboard of the N/O Europe (Bănaru D, unpublished results, Fig. 7). The spatio-temporal overlap between fish sampling and foraging grounds of yelkouan shearwaters revealed in our study provides a rare opportunity to estimate trophic levels and foraging areas from isotopic signatures.

\section{Results}

\subsection{Movements of yelkouan shearwaters and general at-sea distributions of Puffinus shearwater species}

Figure 2 provides a comprehensive view of the at-sea distribution of yelkouan shearwaters and Puffinus shearwater species during the breeding period (May-July) in the Western Mediterranean sea. GPS-tracking data of breeding adults from Port Cros Island in 2011 and 2012 provide detailed information on individual movements during the breeding season (Fig. $2 \mathrm{~A}, \mathrm{~B}$ ), whereas bird densities obtained from vessel-based and aerial surveys conducted in 2012 reveal the general distribution of Puffinus sp. densities at a larger scale (Fig. 2C, D).

Yelkouan shearwaters departed from the colony for two days on average (range 1-5 days) during the chick rearing period (Table 1). Total distance travelled, trip durations and maximal ranges were highly variable between individuals (Table 1). Yelkouan shearwaters travelled on average $428 \mathrm{~km}( \pm 317 \mathrm{~km})$ before returning to the colony to feed their chick. In 2012, average distance travelled was under-estimated because of incomplete tracks. Each year, at least one bird travelled $>1000 \mathrm{~km}$ during a single trip before provisioning its chick (Table 1 ).

In both 2011 and 2012 breeding birds tracked by GPS foraged westwards in coastal waters of the Provencal coast and the Gulf of Lion, between their breeding site and the Spanish border (Fig. 2A, B). Surprisingly, birds hardly ever ventured eastwards of breeding sites, neither outside of the continental shelf ( $200 \mathrm{~m}$ isobath). Tracks were mostly coastal $(<20 \mathrm{~km}$ from the shore) and closer to the shore along the narrow continental shelf of the Provencal coast (Fig. 2A, B).

Aerial surveys conducted during the same period (May 2012), confirmed the coastal distribution of Puffinus shearwater species along the coast of the Gulf of Lion (Fig. 2D). Highest densities of Puffinus shearwaters $\left(>10\right.$ ind $\left.\mathrm{km}^{-1}\right)$ were recorded around the breeding colonies of Hyères Islands (Parc National de Port-Cros) and Marseille Islands (Parc National des Calanques). High densities were also observed outside MPAs, offshore Agde, in the inner part of the Gulf of Lion continental shelf and in very coastal waters close to the Spanish 
border (Parc Naturel Marin du Golfe du Lion). Several high-density spots were recorded along the west coast of Corsica and Sardinia (Fig. 2D).

Our vessel-based survey was conducted later in the breeding season, in July 2012, when adults were rearing large chicks or when chicks were fledging. Similarly to aerial surveys conducted in May 2012, the highest densities of Puffinus shearwaters ( $>20$ individuals. $\mathrm{km}^{-1}$ ) were found off the Rhone delta, in front of the Camargues and Fos-sur-Mer (Fig. 2C). High densities were also recorded offshore Agde in the middle of the Gulf of Lion, along coastal waters of the Parc Naturel Marin du Golfe de Lion and along the Spanish coastline (Fig. 2C).

The observed clustered distribution of densities estimated from vessel-based and aerial surveys suggests local aggregations in favourable areas, in summer.

\subsection{At-sea behaviour and foraging zones of yelkouan shearwaters}

State-space models applied to GPS data enabled estimating the probability for each location to belong to each of the three distinct behavioural states (resting, foraging and travelling). The averaged posterior distribution of the speed parameter was $1.0( \pm 0.2) \mathrm{km}^{-1} \mathrm{~h}^{-1}, 7.2( \pm 3.9)$ $\mathrm{km} . \mathrm{h}^{-1}$ and $34.9( \pm 8.9) \mathrm{km} \cdot \mathrm{h}^{-1}$ for resting, foraging and travelling behaviour respectively. There was low inter-individual variability in daily activity budgets during their foraging trips: Yelkouans spent most of the night time resting on the water $(80 \%$ on average, Table 2$)$. During the day, they spent on average $39 \%$ of their time foraging, $29 \%$ travelling and $32 \%$ resting on water (Table 2). In 2012, yelkouan shearwaters spent less time resting on water during the day compared to 2011 (23\% vs 39\%). Additionally, TDR data revealed that the average percentage of diving locations along individual foraging trips was lower in 2011 compared to 2012 (3.9\% vs $13.5 \%)$. Yelkouan shearwaters dived almost exclusively (99\%) during daytime (Table 2). Dive profiles indicated that the maximum depths reached by adults were $21.2 \mathrm{~m}$ in 2011 and $30.2 \mathrm{~m}$ in 2012 (Table 1).

Foraging locations matched well with diving locations and demonstrated the importance of the peripheral area of the Parc National de Port-Cros and of the core and peripheral areas of the Parc National des Calanques (Fig. 3). Diving and foraging locations along the Spanish Catalan coast were mostly concentrated $\sim 1 \mathrm{~km}$ from the shoreline (Fig. 3). However, foraging locations were also identified offshore Agde and in the eastern part of the Gulf of Lion, in front of the Rhone delta (Fig. 3), confirming the importance of these,non-protected" areas as foraging grounds.

\subsection{Shearwater use of MPAs: behavioural analysis}

Unsurprisingly, all birds tracked by GPS visited waters of the Parc National de Port-Cros, but it is noteworthy that 11 out of 15 individuals (16 out of 20 trips) visited the Parc National des Calanques, whereas 5 individuals ( 5 trips) ventured into the Parc National du Golfe du Lion (Table 3). Overall, $31 \%$ of all GPS locations felt within French MPAs (6\% within the PNM du Golfe du Lion, 5.6 and $7 \%$ within the adjacent and core areas of the Parc National des Calanques, respectively and 12 and $0.3 \%$ within the adjacent and core areas of the Parc National de Port-Cros, respectively, Table 3).

Yelkouan shearwaters frequently dived within MPAs: $37.7 \%$ of diving locations were within MPAs (Table 3). Many diving locations were located in coastal waters $\sim 1 \mathrm{~km}$ from the shoreline within the Parc National de Port-Cros (10.5\%), within the Parc National des Calanques (14\%) and the Parc Marin du Golfe du Lion (12.5\%, Table 3). Yet, most of the diving locations occurred offshore, on the continental shelf of the Gulf of Lion, outside MPAs (Table 3). Similarly, $31 \%$ of foraging locations occurred within MPAs, with $13 \%$ in the Parc 
National des Calanques, $11.5 \%$ in the Parc National de Port-Cros and $7 \%$ in the Parc Marin du Golfe du Lion (Table 3).

\subsection{Post-breeding distribution of failed and successful breeders}

Among the six PTTs deployed, one tag failed to transmit any location in 2012, whereas the others emitted locations to the Argos system for seven to ten weeks depending on individuals (Appendix, Table A.1). Satellite tracking revealed the continued importance of the two National Park peripheral areas as foraging grounds for post-breeding adults (Fig. 4). Most of the locations were located within the Park boundaries and extended to waters off the Rhone delta (Fos-sur-Mer, Fig. 4). The only two birds that travelled East of the breeding colony were the failed breeder (Fig. 4, PY1) equipped in $2011\left(9^{\text {th }}-22^{\text {th }}\right.$ June) and one adult breeder (Fig. 4, PY4) equipped in 2012 ( $7^{\text {th }}$ June-13 ${ }^{\text {th }}$ August). These two birds headed towards the Italian coastline, crossing the Ligurian Sea in less than two days to reach coastal waters off Roma and Napoli, where they stayed for 10 days before the devices stopped (Fig. 4).

\subsection{Inter-breeding distribution of yelkouan and Puffinus shearwater species}

Kernel density distributions of the 15 yelkouan shearwaters tracked concurrently with GLS were estimated for 3 different time periods (July-November, December-January and February-April) to assess temporal variations in distribution and compare it with results of aerial surveys conducted in December 2011-January 2012 (Fig. 5). GLS tracking data showed two different strategies (Fig. 5A): (1) a resident strategy with birds spending all year in the Western Mediterranean Sea, notably in the Gulf of Lion and (2) a migratory strategy, with birds migrating to the Eastern part of the Black Sea for 4 to 5 months (July-late October, see Appendix, Fig. A.3). One third of the equipped birds migrated towards the Black Sea. The two yelkouan shearwaters tracked for two consecutive inter-breeding periods (20112013) showed fidelity to their inter-breeding grounds, in the Gulf of Lion and in the Black Sea, respectively.

Migratory birds thus travelled $3500 \mathrm{~km}$ each way to overwinter in the Black Sea. According to the rapid shift in latitudinal range, birds migrated very fast to the Black Sea, in a couple of days (Appendix, Fig. A.3). The Parc Naturel Marin du Golfe du Lion, appears as a key wintering site for yelkouan shearwaters from December to April (Fig. 5B, C). Half of the winter locations in the Gulf of Lion were over the continent, which according to the low accuracy of GLS, suggests a very coastal distribution during winter, a pattern confirmed by aerial surveys conducted in December - January 2012 (Fig. 5D). Highest densities of Puffinus shearwaters were indeed observed within a $10 \mathrm{~km}$ strip along the coast of the Gulf of Lion, between Marseille and Toulon, offshore the Rhone delta and on the Spanish border. Yelkouans were encountered very occasionally in the oceanic domain surveyed during aerial transects (Fig. 5D).

\subsection{Annual activity pattern}

In addition to light signals, GLS loggers also recorded bird immersion by coding the wet/dry signal. Figure 6 revealed that, whatever their wintering strategy, yelkouan shearwaters spent more than $80 \%$ of their time on the water (sitting or diving) during the inter-breeding period (July-November). Flying activity increased in November, when birds start night time visits to breeding colonies before egg laying in March (Fig. 6). 


\subsection{Trophic status from stable isotope analyses:}

$\delta^{15} \mathrm{~N}$ isotopic values were similar in 2011 and 2012 (t-tests; $\mathrm{P} 1 \mathrm{t}=0.07, \mathrm{df}=68, \mathrm{p}=0.95$; cover feathers: $t=1.64$, df $=70, p=0.10$ ). Yelkouans showed large variability in their $\delta 15 \mathrm{~N}$ signatures during the breeding season (2011: mean $=10.9 \% \pm 1.82 \mathrm{SD}, \min =8.4 \%$ max $=$ $15.0 \%$; 2012: mean $=11.3 \% \pm 1.6 \mathrm{SD}, \min =8.0 \%$, $\max =14.0)$. This $>6 \%$ o difference between the lowest and highest values corresponds to trophic levels comprised between 3.2 and 5.3. According to the isotopic signatures of their potential prey in the western Mediterranean Sea and assuming a trophic enrichment of ca. 3.4\%o between birds and their prey (Søreide et al. 2006), yelkouan shearwater diet could range from being exclusively zooplankton-based to exclusively fish-based during the breeding season.

Hierarchical cluster analyses performed on signatures of P1 feathers consistently identified three main and distinct isotopic groups during the inter-breeding season, in 2011 and 2012. This suggests that yelkouan shearwaters may overwinter in three distinct geographic areas characterized by contrasting $\delta^{13} \mathrm{C}$ signatures (Fig. 7). This finding confirmed GLS results with some individuals wintering in the Black Sea (Group 1) while others stayed in the Mediterranean Sea (Groups 2 and 3, Fig. 7). By coupling information from GLS data with P1 isotopic signatures of 12 individuals recaptured in 2012, we were able to assign the interbreeding foraging ground of each group (Fig. 7B, Militão et al. 2012). One bird had moulted its primary feather before its departure to the Black Sea, in July, since its isotopic signature was similar to that of resident birds (Fig. 7B and Appendix Fig. A.4, yellow profile).

Within-group variance of $\delta^{15} \mathrm{~N}$ isotopic values was lower during the inter-breeding season compared to the breeding season (Fig. 7). However, significant differences in $\delta^{15} \mathrm{~N}$ values were observed between groups (ANOVA, 2011: $F_{2,34}=10.89, p<0.001,2012: F_{2,30}=24.76$, $\mathrm{p}<0.001$ ). Post hoc Tukey"s tests indicated that in 2011, birds from group 3 (presenting the more enriched $\delta^{13} \mathrm{C}$ values) had different $\delta^{15} \mathrm{~N}$ values compared to the two other groups $(p=0.012$ and $p<0.001$ between group 3 and groups 1 and 2, respectively). Groups 1 and 2 showed similar $\delta^{15} \mathrm{~N}$ values $(p=0.23)$. For birds wintering in the Mediterranean Sea, Group 3 fed at a higher trophic level than group $2\left(\mathrm{TL}_{\text {group } 2}=4.1, \mathrm{TL}_{\text {group } 3}=4.6\right)$. In 2012 , both Groups 1 and 3 differed from Group 2 in their $\delta^{15} \mathrm{~N}$ isotopic signatures $(p<0.001)$, with group 3 feeding on higher trophic levels than group $2\left(T L_{\text {group2 }}=4.1, T L_{\text {group3 }}=4.5\right)$. There was no difference between the $\delta^{15} \mathrm{~N}$ values of group 1 and $3(p=0.824)$.

When pooling all inter-breeding groups that stay in the Mediterranean Sea, we found that yelkouan shearwaters had slightly lower $\delta^{15} \mathrm{~N}$ isotopic values during the breeding season than during the inter-breeding one (Mann-Whitney test, $U=1502.5, p=0.01$, means: $P 1=$ $11.1 \%$, cover feathers $=10.6 \%)$, corresponding to a slightly lower trophic level $\left(T L_{\text {breeding }}=\right.$ $4.0, \mathrm{TL}_{\text {inter-breeding }}=4.2$ ).

\section{Discussion}

Our investigation features the first comprehensive study of the at-sea ecology of the Vulnerable yelkouan shearwater and the most extensive single-species study ever conducted on a seabird in metropolitan France. It is also, to our knowledge, one of the first integrative research project that determined the at-sea movements and the distribution of a marine predator using a large spectrum of biotelemetry tracking techniques (satellite tracking, GPS-tracking, geolocation and time-depth recording) in combination with direct observations conducted both from a research vessel and from airplanes (Fig. 2, 3, 4 and 5), as well as with stable isotope analyses (Fig. 7). In particular, movement data gained via GPS tracking were analysed using up-to-date state-space modelling techniques to estimate 
activity budget and map potential important foraging grounds. Overall, our results allow a great leap forward in ecological knowledge relative to yelkouan shearwaters, and such novel information plays a crucial role in validating and refining marine conservation schemes to enhance the conservation of this emblematic Mediterranean species and of the marine megafauna in general.

\subsection{Importance of French MPAs for yelkouan shearwater conservation}

All data gathered from biotelemetry tracking, ship-based and aerial observations concurred to show that birds mainly remained within $20 \mathrm{~km}$ from the coast during the breeding (Fig. 2), post-breeding (Fig. 4) and inter-breeding phases of the annual cycle (Fig. 5). Geolocator data were not sufficiently accurate to support this statement during their inter-breeding season (Fig. 5), yet aerial surveys conducted synoptically do confirm a very coastal distribution even during the inter-breeding period in the Western Mediterranean (Fig. 5). During the breeding season, GPS tracking showed that $31 \%$ of yelkouan at-sea activities were conducted within MPAs situated along the French continental Mediterranean coast (Fig. 3 and Table 2), while $31 \%$ of foraging and $38 \%$ of diving locations occurred within these zones (Fig. 3 and Table 3 ). This is a remarkable score, knowing that these MPAs were not primarily designed for seabird conservation, but rather for preserving coastal fish (such as the Dusky Grouper, Epinephelus marginatus), benthic biota (Francour et al., 2001) or deep-sea ecosystems (Davies et al., 2007). Similarly, $26.8 \%$ of resting locations were located within MPAs and were likely associated to the "rafting" behaviour of yelkouan shearwaters which build gregarious resting parties, often close to their breeding sites. These rafts allow resting, but also might function as information centres (Ward and Zahavi 1973). Protect rafting areas is important since disturbing the birds could both jeopardize their energy balance and their social structure, with a likely impact on breeding propensity, breeding success (disturbed birds might refrain from attending the colony and might lose track of potential breeding partners) and foraging success (if birds gather information on profitable feeding areas from those rafts). At the moment, yelkouan rafting areas are threatened by daytime boat traffic and floating night-clubs which are rapidly spreading around islands of the French Riviera, such as Frioul Island (Patrick Vidal personal communication), within the adjacent marine extension of the Parc National des Calanques in summer.

Attendance and behaviour of yelkouan shearwaters varied between MPAs: state-space models indicated that waters of the Parc National des Calanques were very profitable foraging areas, with most of equipped birds visiting this MPA (84\%) and $14 \%$ of all diving locations occurring within the extended marine area of the National Park. This finding suggests that the Marseille islands could probably sustain larger populations than the current 31-41 pairs of yelkouan shearwaters (Bourgeois 2011). Massive predation by rats has probably been a strong limiting factor to population growth. The Parc Naturel Marin du Golfe du Lion was less exploited by shearwaters during the breeding season due to its longer distance from the breeding colonies but proved to be a crucial foraging area during the interbreeding season (from December-April).

Further, our results showed highly coastal flight corridors outside MPAs, which make yelkouan shearwaters particularly Vulnerable to at-sea threats or new obstacles within $20 \mathrm{~km}$ from the shore. For instance our GPS tracking of breeding individuals showed that the wind turbine park planned off Fos-sur-Mer (Fig. 2) lays exactly on a yelkouan flight corridor connecting the Marseille and Toulon breeding populations with their feeding grounds in the inner Gulf of Lion. Furthermore, when considering the spatial scale of post-breeding and inter-breeding movements along the Spanish and Italian coast or the Black Sea, populations of Puffinus shearwater species obviously require transboundary conservation efforts (Louzao et al., 2012). 


\subsection{Feeding strategy and trophic ecology}

We found great diving capabilities (frequent dives $>10 \mathrm{~m}$, maximum dive depth: $30 \mathrm{~m}$; Table 1) clearly surpassing those of the larger, sympatric Scopoli"s shearwater which rarely dives $>$ $4 \mathrm{~m}$ (Péron C., unpublished results). Such diving habits informed about the marine strata over which yelkouans are susceptible to interfere lethally with fishing gear. Besson (1973) reported large mortality events in fishing gears (20-50m deep) in March 1972 within coastal waters of cap Sicié (east of Toulon). Cap Sicié has indeed been identified in our study as a key flyway and feeding area for yelkouan shearwaters throughout its annual cycle (Fig. 2, 3 and 4).

From a trophic point of view, yelkouan shearwaters are considered as mainly dependent upon small pelagic fish during the incubation and chick rearing period (Bourgeois et al. 2011). However, our stable isotopic analyses suggest a wider diet than previously reported, ranging from zooplankton to pelagic fish, especially during the breeding season (Fig. 7). The large variability in isotopic signatures may result from inter-individual differences in timing of moult in yelkouan shearwaters; more studies are required on this topic to refine interpretation of isotopic analyses. Foraging locations inferred from state-space models were far more numerous than diving locations, suggesting that yelkouans spent more time searching for food and/or feeding than diving. Yelkouans are also probably able to seize prey such as krill or fish larvae from the sea surface.

These results do indicate that even if yelkouan shearwaters remain confined to coastal areas subjected to strong natural and human-induced environmental change (Lejeusne et al., 2010), they may nonetheless benefit from flexible feeding strategies and from a very broad diet during the breeding season, something which could play an important role in their resilience and population persistence in the Mediterranean Sea. Interestingly, the collapse in sardine (Sardina pilchardus) stock and low anchovy (Engraulis encrasicolus) biomass observed in the Gulf of Lion over the past six years (GFCM 2011) did not stop yelkouan shearwaters from foraging in this area.

\subsection{Implications for marine conservation planning}

On the basis of these series of important findings, we validate our hypothesis of the paramount importance of coastal MPAs for the population persistence of yelkouan shearwaters in the Mediterranean. MPAs are being designed and implemented across the planet as a response to the rapid erosion of marine biodiversity (Worm et al., 2006) and to the degradation of marine trophic functioning (Pauly et al., 1998). As such, MPAs are considered as one of the tools of the ecosystem-based management of the oceans (Cury et al., 2008). The European Union is pressing its member states to convert $10 \%$ of their EEZ to MPAs by 2020. This process is often being conducted in haste, as in a sort of „MPA gold rush", and both scientists and conservationists are increasingly worried about the actual conservation value of MPAs, as well as about the legal specificities of MPAs. For instance, France is willing to massively extend its MPAs network, yet this should not follow a major weakening in the legislation. The marine park of Port Cros has for instance recently been extended to the neighbouring area of Porquerolles, but within this new MPA, fishing is continued by dozens of recreational fishing vessels under an anteriority right. Moreover, Porquerolles southern coast, a key area for all yelkouan (Fig. 3E, 4) and Scopoli"s shearwaters (Péron, unpubl. data) tracked during our study, is subjected to increasing interest by fishermen, putting continued pressure onto park managers to open this area to longlining, the most damaging fishing activity regarding seabird bycatch. This edifying 
example is not an isolated case and there is therefore a major risk that MPAs will be established around the world to please policymakers, but will remain ,paper parks" with little or no conservation value for marine megafauna (Chuenpagdee et al., 2013). Scientists have a key role to play in this context since they are capable of defining MPAs using objective criteria (Edgar et al., 2007), but also of testing their operational efficiency (e.g. Pichegru et al., 2010). For instance, Pichegru et al. (2012) demonstrated that small-size MPAs (,no-take" zone) have limited benefit for marine predators when fishing pressure increases at reserve boundaries. There is also an ongoing debate on whether fixed MPAs (in space and time) will be of any value for the conservation of the highly mobile megafauna (Game et al., 2009). Adaptive marine management based on spatio-temporally flexible MPAs seems a reasonable, yet logistically challenging answer to this problem, but there is also hope that fixed MPAs may nonetheless at least partly contribute to the conservation of the marine megafauna (Game et al., 2009; Hooker et al. 2011).

Beyond this specific case, our study is an important contribution to ongoing research efforts assessing the pertinence of MPAs for the conservation of the mobile marine megafauna (Hooker and Gerber 2004; Scott et al., 2012) and confirms the relevance of seabird tracking data for defining these areas. This occurs within the worldwide effort to designate marine Important Bird Areas (BirdLife International 2013: http://54.247.127.44/marinelBAs/default.html). Whether such "seabird-MPAs" can also be used as conservation umbrellas for the multi-trophic conservation of ocean biota is clearly open to debate (Zacharias and Roff 2001). Yet, seabirds (including Puffinus species) have been recently identified as keystone species in the food web of the Gulf of Lion (Bănaru et al. 2013) and our study suggests that it is far more cost-and time-effective to gather seabird specific spatial ecology data than to conduct entire trophic network analyses before defining the ecologically most pertinent MPAs.

\section{Acknowledgements}

This study was funded by the French Agency for Marine Protected Areas within the "Programme PACOMM, Natura2000 en mer" and by the French Ministry in charge of the Environment (Ministère de l'Ecologie, du Développement Durable et de l'Energie) for the aerial surveys. We are very grateful to the Parc National de Port-Cros for their authorization to conduct our biotelemetry study on yelkouan colonies, and particularly Pascal Gillet and Karen Bourgeois for their strong support and advices during fieldwork. We also thank JeanBaptiste Pons, Karen Bourgeois, Peggy Fournial, Marine Bely, Marion Kriloff and Sylvain Dromzee for their investment in the night time biotelemetry fieldwork, and Nory El Ksaby for preparation of feathers samples. We are grateful to Daniela Bănaru (Mediterranean Institute of Oceanography, Marseille) for preparing fish samples for isotopic analyses and her valuable comments on the manuscript. We acknowledge the crew of the Ifremer RV Europe, in particular Jean-Louis Bigot chief scientist onboard. We are grateful to Léa David, Eric Stéphan, Nathalie Di-Meglio, Ariane Blanchard, Alessio Maglio, Vincent Bretille, Marie Pellé, Sandrine Serre, Cécile Dars, Morgane Perri, Emilie Durand, Thomas Barraud, Alexis Chevalier and to our partners Pixair Survey and Sinay for their investment in aerial surveys. We also thank Vincent Bretagnolle (Centre d'Etudes Biologiques de Chizé, CNRS) for its contribution to the aerial survey design and Gaël Guillou and Pierre Richard for stable isotopic analyses at LIENSs (University of La Rochelle). 


\section{References}

Arcos, J. M., Louzao, M., and Oro, D. (2008). Proceedings of the Fourth World Fisheries Congress: Reconciling Fisheries with Conservation, chapter Fishery ecosystem impacts and management in the Mediterranean: seabirds point of view, pages 587-596. American Fisheries Society, Symposium 49, Bethesda, MD, USA.

Bănaru, D., Mellon-Duval, C., Roos, D., Bigot, J-L, Souplet, A., Jadaud, A., Beaubrun, P., and Fromentin, J-M (2012). Trophic structure in the gulf of lions marine ecosystem (north-western mediterranean sea) and fishing impacts. Journal of Marine Systems.

Bearhop, S., Waldron, S., Votier, S. C., and Furness, R. W. (2002). Factors that influence assimilation rates and fractionation of nitrogen and carbon stable isotopes in avian blood and feathers. Physiological and Biochemical Zoology, 75(5):451-458.

Besson, J. (1973). Remarques sur la mort accidentelle de puffins yelkouan. Alauda, XLI:165-167.

Blondel, J., Aronson, J., Bodiou, J., and Boeuf, G. (2010). The Mediterranean region: biological diversity through time and space. Oxford University Press, Oxford.

Bonnaud, E., Bourgeois, K., Vidal, E., Kayser, Y., Tranchant, Y., and Legrand, J. (2007). Feeding ecology of a feral cat population on a small mediterranean island. Journal of Mammalogy, 88(4):1074-1081.

Borg, J., Raine, H., Raine, A., and Barbara, N. (2010). Protecting malta"s wind chaser. Technical report, The EU Life Yelkouan Project Report. BirdLife Malta, Valletta Malta.

Bourgeois (2011). The Yelkouan shearwater Puffinus Yelkouan. Updated state of knowledge and conservation of the nesting populations of the small Mediterranean islands. Initiative PIM. 23p. http://www.initiative-pim.org/

Bourgeois, K., Vorenger, J., Faulquier, L., Legrand, J., and Vidal, E. (2011). Diet and contamination of the yelkouan shearwater puffinus yelkouan in the Hyères archipelago, mediterranean basin, france. Journal of Ornithology, 152(4):947-953.

Camphuysen, C.J., G. S. (2004). Recording foraging seabirds at sea: Standardised recording and coding of foraging behaviour and multi-species foraging associations. Atlantic Seabirds. 6:1-32.

Capizzi, D., Baccetti, N., and Sposimo, P. (2010). Prioritizing rat eradication on islands by cost and effectiveness to protect nesting seabirds. Biological Conservation, 143(7):1716-1727.

Cardona, L., de Quevedo, I. A., Borrell, A., and Aguilar, A. (2012). Massive consumption of gelatinous plankton by mediterranean apex predators. PloS one, 7(3):e31329.

Chuenpagdee, R., Pascual-Fernández, J. J., Szeliánszky, E., Luis Alegret, J., Fraga, J., and Jentoft, S. (2013). Marine protected areas: Re-thinking their inception. Marine Policy, 39:234-240.

Coll, M., Piroddi, C., Albouy, C., Ben Rais Lasram, F., Cheung, W.W.L., Christensen,V., Karpouzi, V.S., Guilhaumon, F., Mouillot, D., Paleczny, M. et al. (2012). The mediterranean sea under siege: spatial overlap between marine biodiversity, cumulative threats and marine reserves. Global Ecology and Biogeography, 21(4):465-480.

Cury, P. M., Shin, Y.-J., Planque, B., Durant, J. M., Fromentin, J.-M., Kramer-Schadt, S., Stenseth, N. C., Travers, M., and Grimm, V. (2008). Ecosystem oceanography for global change in fisheries. Trends in Ecology \& Evolution, 23(6):338-346. 
Cury, P. M., Boyd, I. L., Bonhommeau, S., Anker-Nilssen, T., Crawford, R. J., Furness, R. W., Mills, J. A., Murphy, E. J., Österblom, H., Paleczny, M., et al. (2011). Global seabird response to forage fish depletion : one-third for the birds. Science, 334(6063):1703-1706.

Davies, A. J., Roberts, J. M., and Hall-Spencer, J. (2007). Preserving deep-sea natural heritage: emerging issues in offshore conservation and management. Biological Conservation, 138(3):299-312.

Edgar, G., Russ, G., and Babcock, R. (2007). Marine Ecology, chapter Marine Protected Areas, pages 533-555. Oxford University Press, South Melbourne, VIC, Australia.

Francour, P., Harmelin, J.-G., Pollard, D., and Sartoretto, S. (2001). A review of marine protected areas in the northwestern mediterranean region: siting, usage, zonation and management. Aquatic Conservation: Marine and Freshwater Ecosystems, 11(3):155188.

Fredj, G., Bellan-Santini, D., and Meinardi, M. (1992). Etat des connaissances sur la faune méditerranéenne. Bulletin de I"Institut Océanographique de Monaco, 9:133-145.

Game, E. T., Grantham, H. S., Hobday, A. J., Pressey, R. L., Lombard, A. T., Beckley, L. E., Gjerde, K., Bustamante, R., Possingham, H. P., and Richardson, A. J. (2009). Pelagic protected areas: the missing dimension in ocean conservation. Trends in ecology \& evolution, 24(7):360-369.

Garthe, S. and Hüppop, O. (2004). Scaling possible adverse effects of marine wind farms on seabirds: developing and applying a vulnerability index. Journal of Applied Ecology, 41(4):724-734.

GFCM (2011). Report of the thirteenth session of the scientific advisory committee. marseille, france. Technical report, FAO Fisheries and Aquaculture.

Grémillet, D., Lewis, S., Drapeau, L., van der Lingen, C., Huggett, J., Coetzee, J., Verheye, H., Daunt, F., Wanless, S., and Ryan, P. (2008). Spatial match-mismatch in the benguela upwelling zone: should we expect chlorophyll and sea-surface temperature to predict marine predator distributions? Journal of Applied Ecology, 45(2):610-621.

Grémillet, D. and Boulinier, T. (2009). Spatial ecology and conservation of seabirds facing global climate change: a review. Marine Ecology-Progress Series, 391:121-137.

Guilford, T., Wynn, R., McMinn, M., Rodrguez, A., Fayet, A., Maurice, L., Jones, A., and Meier, R. (2012). Geolocators reveal migration and pre-breeding behaviour of the critically endangered balearic shearwater puffinus mauretanicus. PloS one, 7(3):e33753.

Hammond, P.S., Macleod, K., Berggren, P., Borchers, D.L., Burt, L., Cañadas, A., Desportes, G., Donovan, G.P., Gilles, A., Gillespie, D et al. (2013). Cetacean abundance and distribution in European Atlantic shelf waters to inform conservation and management. Biological Conserversation 164, 107-122.

Hobson, K. A. and Bond, A. L. (2012). Extending an indicator: year-round information on seabird trophic ecology from multiple-tissue stable-isotope analyses. Marine Ecology Progress Series, 461:233-243.

Hooker, S. K. and Gerber, L. R. (2004). Marine reserves as a tool for ecosystem-based management: the potential importance of megafauna. BioScience, 54(1):27-39.

Hooker, S.K., Cañadas A., Hyrenbach, K.D., Corrigan, C., Polovina, J.J., and Reeves, R.R. (2011). Making protected area networks effective for marine top predators. Endangered Species Research, 13:203-218.

BirdLife International (2013) Calonectris Diomedea. In: IUCN 2012 IUCN Red List of Threatened Species. Version 20122 <www iucnredlist.org>. Downloaded on 02 May 2013. 
Kelly, J. F. (2000). Stable isotopes of carbon and nitrogen in the study of avian and mammalian trophic ecology. Canadian Journal of Zoology, 78(1):1-27.

Laneri, K., Louzao, M., Martnez-Abran, A., Arcos, J., Belda, E., Guallart, J., Sánchez, A., Giménez, M., Maestre, R., and Oro, D. (2010). Trawling regime influences longline seabird bycatch in the mediterranean: new insights from a small-scale fishery. Marine Ecology Progress Series, 420:241-252.

Lejeusne, C., Chevaldonné, P., Pergent-Martini, C., Boudouresque, C. F., and Pérez, T. (2010). Climate change effects on a miniature ocean: the highly diverse, highly impacted mediterranean sea. Trends in Ecology \& Evolution, 25(4):250-260.

Louzao, M., Hyrenbach, K. D., Arcos, J. M., Abello, P., Sola, L. G. d., and Oro, D. (2006). Oceanographic habitat of an endangered mediterranean procellariiform: implications for marine protected areas. Ecological Applications, 16(5):1683-1695.

Louzao, M., Delord, K., Garcá, D., Boué, A., and Weimerskirch, H. (2012). Protecting persistent dynamic oceanographic features: Transboundary conservation efforts are needed for the critically endangered balearic shearwater. PloS one, 7(5):e35728.

Militão, T., Bourgeois, K., Roscales, J. L., and González-Solís, J. (2012). Individual migratory patterns of two threatened seabirds revealed using stable isotope and geolocation analyses. Diversity and Distributions, 19(3):317-329.

Morales, J. M., Haydon, D. T., Frair, J., Holsinger, K. E., and Fryxell, J. M. (2004). Extracting more out of relocation data: building movement models as mixtures of random walks. Ecology, 85(9):2436-2445.

Myers, N., Mittermeier, R. A., Mittermeier, C. G., Da Fonseca, G. A., Kent, J., et al. (2000). Biodiversity hotspots for conservation priorities. Nature, 403(6772):853-858.

Oppel, S., Raine, A. F., Borg, J. J., Raine, H., Bonnaud, E., Bourgeois, K., and Breton, A. R. (2011). Is the yelkouan shearwater puffinus yelkouan threatened by low adult survival probabilities? Biological Conservation, 144(9):2255-2263.

Oro, D., Cam, E., Pradel, R., and Martnez-Abran, A. (2004). Influence of food availability on demography and local population dynamics in a long-lived seabird. Proceedings of the Royal Society of London. Series B: Biological Sciences, 271(1537):387-396.

Papiol, V., Cartes, J., Fanelli, E., and Rumolo, P. (2013). Food web structure and seasonality of slope megafauna in the nw mediterranean elucidated by stable isotopes: Relationship with available food sources. Journal of Sea Research, 77:53-69.

Pauly, D., Christensen, V., Dalsgaard, J., Froese, R., and Torres Jr, F. (1998). Fishing down marine food webs. Science, 279(5352):860-863.

Phillips, R., Silk, J., Croxall, J., Afanasyev, V., and Briggs, D. (2004). Accuracy of geolocation estimates for flying seabirds. Marine Ecology-Progress Series, 266:265-272.

Pichegru, L., Gremillet, D., Crawford, R., and Ryan, P. (2010). Marine no-take zone rapidly benefits endangered penguin. Biology Letters, 6(4):498-501.

Pichegru, L., Ryan, P.G., van Eeden, R., Reid, T., Grémillet, D., Wanless, R. (2012). Industrial fishing, no-take zones and endangered penguins. Biological Conservation, 156:117-125.

Post, D. M. (2002). Using stable isotopes to estimate trophic position: models, methods, and assumptions. Ecology, 83(3):703-718.

Raine, A. F., Borg, J. J., Raine, H., and Phillips, R. A. (2013). Migration strategies of the yelkouan shearwater puffinus yelkouan. Journal of Ornithology, 154:411-422.

Ruffino, L., Bourgeois, K., Vidal, E., Duhem, C., Paracuellos, M., Escribano, F., Sposimo, P., Baccetti, N., Pascal, M., and Oro, D. (2009). Invasive rats and seabirds after 2,000 years 
of an unwanted coexistence on mediterranean islands. Biological invasions, 11(7):16311651.

Sanpera, C., Moreno, R., Ruiz, X., Jover, L., et al. (2007). Audouin"s gull chicks as bioindicators of mercury pollution at different breeding locations in the western mediterranean. Marine pollution bulletin, 54(6):691-696.

Scott, R., Hodgson, D. J., Witt, M. J., Coyne, M. S., Adnyana, W., Blumenthal, J. M., Broderick, A. C., Canbolat, A. F., Catry, P., Ciccione, S., et al. (2012). Global analysis of satellite tracking data shows that adult green turtles are significantly aggregated in marine protected areas. Global Ecology and Biogeography, 21:1053-1061.

Søreide, J. E., Hop, H., Carroll, M. L., Falk-Petersen, S., and Hegseth, E. N. (2006). Seasonal food web structures and sympagic-pelagic coupling in the european arctic revealed by stable isotopes and a two-source food web model. Progress in Oceanography, 71(1):59-87.

Tasker, M., Hope Jones, P., Dixon, T., and Blake, B. (1984). Counting seabirds at sea from ships : a review of methods employed and a suggestion for a standardized approach. The Auk, 101:567-577.

Ward, P. and Zahavi, A. (1973). The importance of certain assemblages of birds as "information-centres" for food-finding. Ibis, 115(4):517-534.

Weiss, F., Furness, R. W., McGill, R. A., Strange, I. J., Masello, J. F., and Quillfeldt, P. (2009). Trophic segregation of Falkland islands seabirds: insights from stable isotope analysis. Polar biology, 32(12):1753-1763.

Wilson, R., Ducamp, J., Rees, G., Culik, B., and Niekamp, K. (1992). Estimation of location: global coverage using light intensity. In Priede IM, S. S., editor, Wildlife telemetry: remote monitoring and tracking of animals, volume Priede IM,Swift SM, pages 131-134. Ellis Horward, Chichester.

Worm, B., Barbier, E. B., Beaumont, N., Duffy, J. E., Folke, C., Halpern, B. S., Jackson, J. B., Lotze, H. K., Micheli, F., Palumbi, S. R., et al. (2006). Impacts of biodiversity loss on ocean ecosystem services. Science, 314(5800):787-790.

Zacharias, M. A. and Roff, J. C. (2001). Use of focal species in marine conservation and management: a review and critique. Aquatic Conservation: Marine and Freshwater Ecosystems, 11(1):59-76.

Zotier (1997). Biogéographie des oiseaux marins en Méditerranée et écologie d"un Procellariiforme endémique: le puffin de Méditerranée Puffinus yelkouan. PhD thesis, EPHE - university of Montpellier 2, France.

Zotier, R., Bretagnolle, V., and Thibault, J.-C. (2003). Biogeography of the marine birds of a confined sea, the mediterranean. Journal of Biogeography, 26(2):297-313. 
Table 1: Foraging trip characteristics of breeding adult yelkouan shearwaters equipped with GPS and TDR on Port Cros in May-June 2011 and 2012. Averages are given \pm SD, followed by [min-max] and sample size corresponding to the number of individuals and trips ( $n=$ individuals-trips) since few birds did multiple trips. Only complete tracks were included in the calculation of trips characteristics.

\begin{tabular}{|c|c|c|c|c|}
\hline $\begin{array}{c}\text { Year (May-June) } \\
\text { Chick-rearing period }\end{array}$ & $\begin{array}{c}\text { Trip } \\
\text { duration (day) }\end{array}$ & $\begin{array}{l}\text { Max range } \\
(\mathrm{km})\end{array}$ & $\begin{array}{l}\text { Total travelled } \\
\text { distance }(\mathrm{km})\end{array}$ & $\begin{array}{c}\text { Max depth (m) } \\
\text { Mean [min-max] }\end{array}$ \\
\hline $\begin{array}{l}2011 \\
n=7-10\end{array}$ & $\begin{array}{l}2.2 \pm 1.3 \\
{[0.8-5.0]}\end{array}$ & $\begin{array}{l}154.4 \pm 82.6 \\
{[47.4-269.4]}\end{array}$ & $\begin{array}{c}549.7 \pm 362.4 \\
{[148.1-1179.6]}\end{array}$ & $\begin{array}{c}15.0 \\
{[6.5-21.2]} \\
n=3\end{array}$ \\
\hline $\begin{array}{l}2012 \\
n=8-8\end{array}$ & $\begin{array}{l}1.3 \pm 0.5 \\
{[0.8-2.0]}\end{array}$ & $\begin{array}{c}88.4 \pm 68.5 \\
{[13.2-203.3]}\end{array}$ & $\begin{array}{c}275.4 \pm 167.5 \\
{[91.5-581.0]}\end{array}$ & $\begin{array}{c}19.1 \\
{[9.2-30.2]} \\
n=7\end{array}$ \\
\hline $\begin{array}{l}2011 \& 2012 \\
n=15-18\end{array}$ & $\begin{array}{l}1.8 \pm 1.1 \\
{[0.8-5.0]}\end{array}$ & $\begin{array}{l}125.1 \pm 81.8 \\
{[13.2-269.4]}\end{array}$ & $\begin{array}{l}427.8 \pm 317.4 \\
{[91.5-1179.6]}\end{array}$ & $\begin{array}{c}17.8 \\
{[6.5-30.2]} \\
n=10\end{array}$ \\
\hline
\end{tabular}

Table 2: Average daily activity budgets of breeding yelkouan shearwaters in 2011 and 2012 . Behavioural states were estimated by state space models, applied to GPS tracking data. Sample sizes refer to the number of complete tracking days and birds tracked. Percentages of diving locations were estimated independently, from TDR fitted on three and seven individuals in 2011 and 2012, respectively. Max and min are indicated in brackets.

\begin{tabular}{|c|c|c|c|c|c|}
\hline \multicolumn{2}{|c|}{$\begin{array}{c}\text { Year (May-June) } \\
\text { Chick-rearing period }\end{array}$} & $\begin{array}{c}\text { \% resting on water } \\
\text { Mean } \\
{[\text { min-max }]}\end{array}$ & $\begin{array}{c}\% \text { foraging } \\
\text { Mean } \\
{[\text { min-max] }}\end{array}$ & $\begin{array}{c}\% \text { travelling } \\
\text { Mean } \\
{[\text { min-max }]}\end{array}$ & $\begin{array}{c}\% \text { diving locations } \\
\text { Mean } \\
{[\min -\max ]}\end{array}$ \\
\hline $\begin{array}{l}\quad 2011 \\
n=18 \text { days } \\
n=6 \text { individuals }\end{array}$ & $\begin{array}{l}\text { Day } \\
\text { Night }\end{array}$ & $\begin{array}{c}39.5 \\
{[7.4-55.1]} \\
79.3 \\
{[57.3-90.6]}\end{array}$ & $\begin{array}{c}35.0 \\
{[20.1-53.7]} \\
11.6 \\
{[6.2-19.0]}\end{array}$ & $\begin{array}{c}25.4 \\
{[4.4-38.9]} \\
9.0 \\
{[0-30.2]} \\
\end{array}$ & $\begin{array}{c}3.9 \\
{[1.4-6.7]} \\
0.09 \\
{[0-0.4]}\end{array}$ \\
\hline $\begin{array}{l}\quad \mathbf{2 0 1 2} \\
\mathrm{n}=15 \text { days } \\
\mathrm{n}=7 \text { individuals }\end{array}$ & $\begin{array}{l}\text { Day } \\
\text { Night }\end{array}$ & $\begin{array}{c}22.9 \\
{[0.8-42.7]} \\
80.3 \\
{[52.8-95.3]}\end{array}$ & $\begin{array}{c}44.0 \\
{[21.8-81.2]} \\
14.8 \\
{[4.6-43.8]}\end{array}$ & $\begin{array}{c}33.0 \\
{[11.8-63.6]} \\
4.9 \\
{[0-13.9]}\end{array}$ & $\begin{array}{c}13.5 \\
{[4.1-24.1]} \\
0.12 \\
{[0-0.8]}\end{array}$ \\
\hline $\begin{array}{l}\mathbf{2 0 1 1} \& \mathbf{2 0 1 2} \\
\mathrm{n}=33 \text { days } \\
\mathrm{n}=13 \text { individuals }\end{array}$ & $\begin{array}{l}\text { Day } \\
\text { Night }\end{array}$ & $\begin{array}{c}31.9 \\
{[0.8-55.1]} \\
79.7 \\
{[52.8-95.3]}\end{array}$ & $\begin{array}{c}39.1 \\
{[20.1-81.2]} \\
13.0 \\
{[4.6-43.8]}\end{array}$ & $\begin{array}{c}28.9 \\
{[4.4-63.6]} \\
7.2 \\
{[0.0-30.2]}\end{array}$ & $\begin{array}{c}10.1 \\
{[1.4-24.1]} \\
0.1 \\
{[0-0.8]}\end{array}$ \\
\hline
\end{tabular}


Table 3: Frequentation and utilization of MPAs waters by breeding yelkouan shearwaters during the chick rearing period (May-June 2011 and 2012).

\begin{tabular}{|l|c|c|c|c|c|c|c|}
\hline \multicolumn{1}{|c|}{ Zone } & $\begin{array}{c}\text { Outside } \\
\text { MPAs }\end{array}$ & $\begin{array}{c}\text { Parc National } \\
\text { Calanques } \\
\text { adjacent }\end{array}$ & $\begin{array}{c}\text { Parc National } \\
\text { Calanques } \\
\text { core }\end{array}$ & $\begin{array}{c}\text { Parc National } \\
\text { Port-Cros } \\
\text { adjacent }\end{array}$ & $\begin{array}{c}\text { Parc National } \\
\text { Port-Cros } \\
\text { core }\end{array}$ & $\begin{array}{c}\text { Parc Naturel } \\
\text { Marin du } \\
\text { Golfe du Lion }\end{array}$ & $\begin{array}{c}\text { Total } \\
\text { within } \\
\text { MPAs }\end{array}$ \\
\hline No. trips (/20) & 19 & 16 & 14 & 20 & 11 & 5 & 20 \\
No.bird (/15) & 12 & 11 & 11 & 15 & 7 & 5 & 15 \\
\hline \% occurrence & 69.1 & 5.6 & 7.1 & 12.3 & 0.3 & 5.7 & 30.9 \\
\% diving locations & 62.3 & 8.6 & 6.1 & 10.0 & 0.5 & 12.5 & 37.7 \\
\% foraging locations & 69.1 & 5.1 & 7.3 & 11.3 & 0.4 & 6.8 & 30.9 \\
\% resting locations & 73.2 & 5.0 & 4.9 & 10.6 & 0.2 & 6.1 & 26.8 \\
\% travelling locations & 63.3 & 7.0 & 10.3 & 15.8 & 0.3 & 3.4 & 36.7 \\
\hline
\end{tabular}

\section{Figures}

Figure 1: Location of the Port Cros and Porquerolles study colonies and the other yelkouan shearwater breeding colonies. French marine protected areas are delimited by solid black lines and $200 \mathrm{~m}$ isobaths by grey lines.

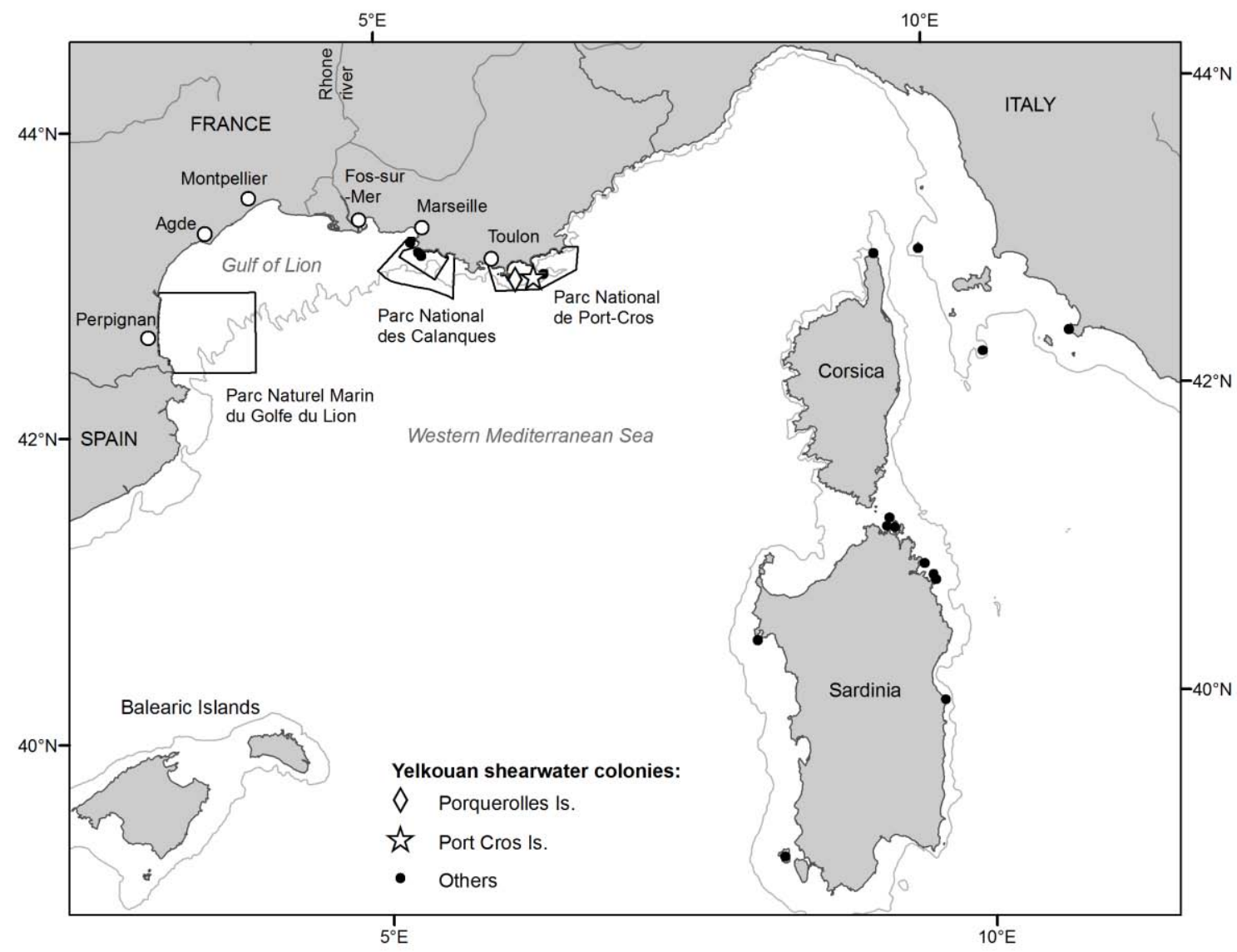


Figure 2 : Distribution of yelkouan shearwaters during the breeding season from three methodologies : A) foraging trips of seven adults GPS-tracked during the chick rearing period in 2011 (each colour corresponds to a single individual), B) foraging trips of 13 adults GPStracked during the chick rearing period in 2012 (each colour corresponds to a single individual), C) Bird densities calculated from vessel-based sightings during the PELMED cruise conducted in July 2012 on board RV N/O L'Europe, by IFREMER and D) Bird densities calculated along aerial transects conducted by the Observatoire PELAGIS (SAMM 2012), in May 2012. The $200 \mathrm{~m}$ isobath is drawn background with a grey line, as well as the coastal zone $(<12 \mathrm{~nm}$ from the shore) in clear grey.
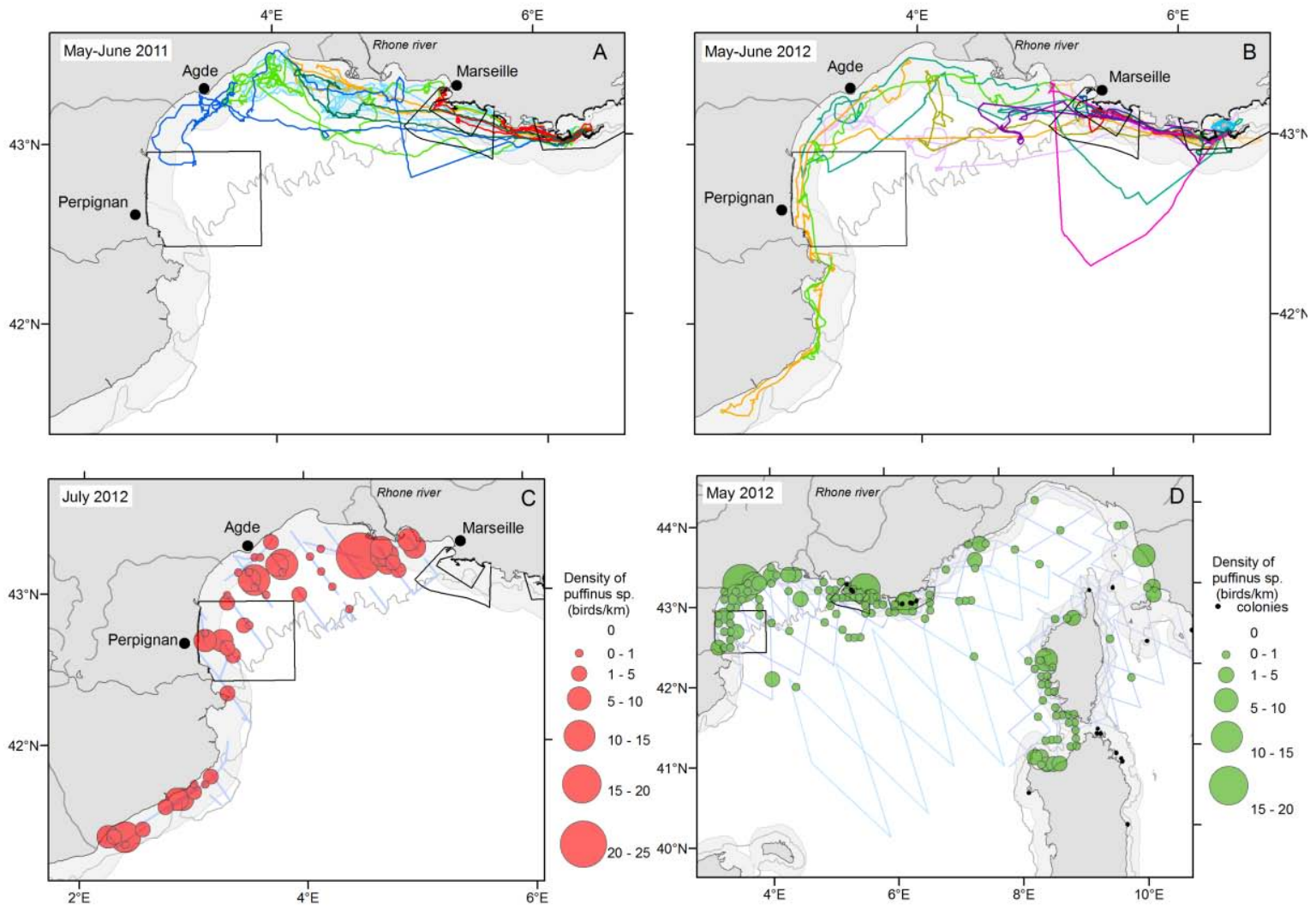
Figure 3: Distribution of foraging and diving locations along trips (thin grey lines) of breeding yelkouan shearwaters equipped with GPS in Port Cros Island. Locations identified by statespace models as foraging diving positions recorded by TDR are color-coded. Panels 2C, 2D and 2E zoom into each particular MPA for 2011 and 2012 with the same color-code. The 200 $m$ isobath is drawn background with a grey line.
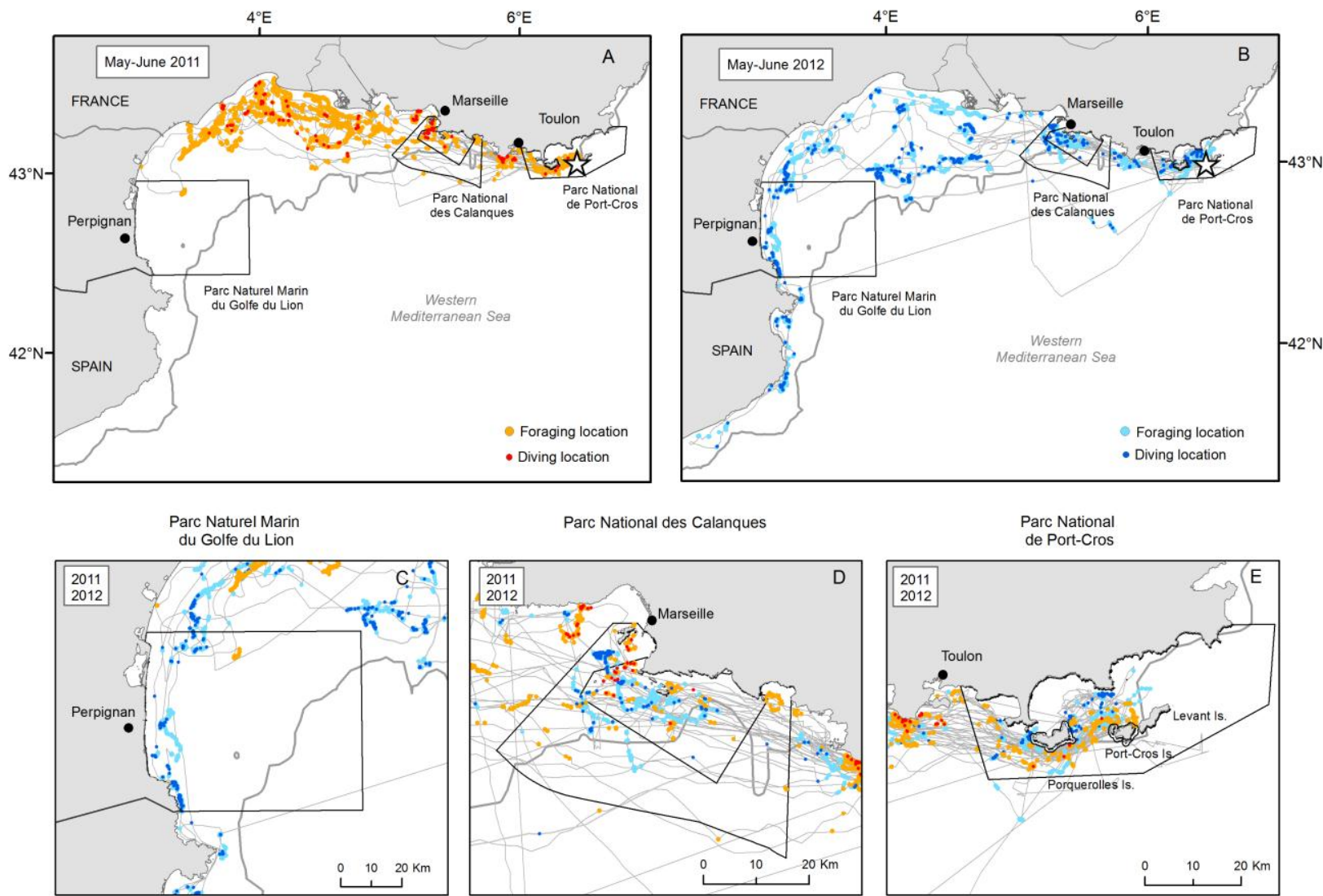
Figure 4: Positions of one failed-breeder yelkouan shearwater (PY1, equipped in 2011) and four post-breeding adults (PY2-5, equipped in 2012) tracked between mid-June and August (i.e. after their breeding season) by solar PTTs along the French Riviera (main map) and the Italian Tyrrhenian coast (insert). White stars indicate the positions of yelkouan shearwater breeding colonies and the back star, Port-Cros Is., the study colony.

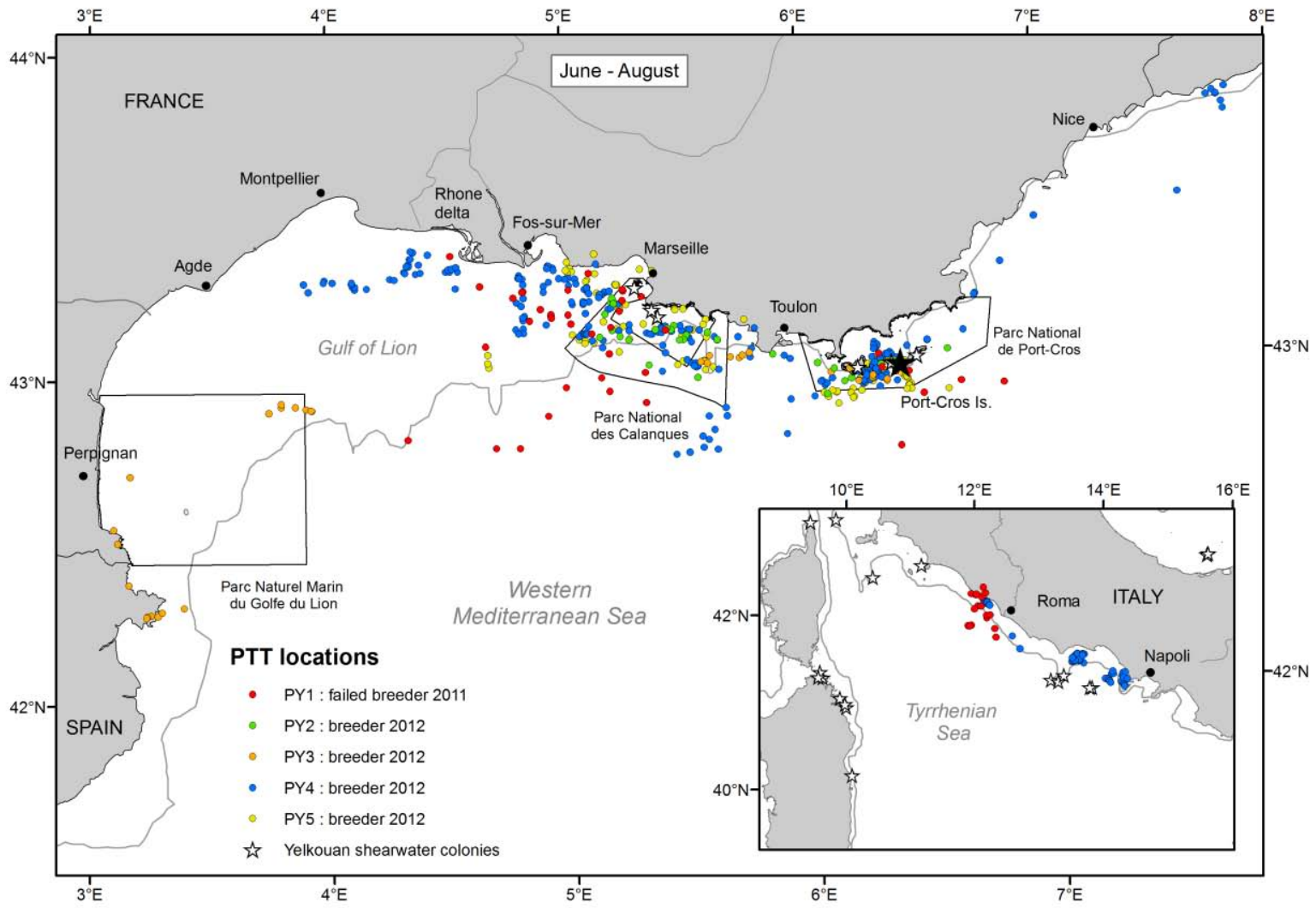


Figure 5: Kernel density distributions of 15 yelkouan shearwaters tracked with geolocators across the inter-breeding period (2011-2012). Kernel density contours represented on panels A, B and C, correspond to spatial extent of shearwater range ( $70 \% \mathrm{UD})$, focal areas (50\% UD) and core areas (25, 10 and 5\% UD) at different period of the year. Two thirds of the birds remained within the western Mediterranean while one third migrated to the Black sea. Panel D represents densities of Puffinus shearwater species observed by aerial surveys in December-January 2012.
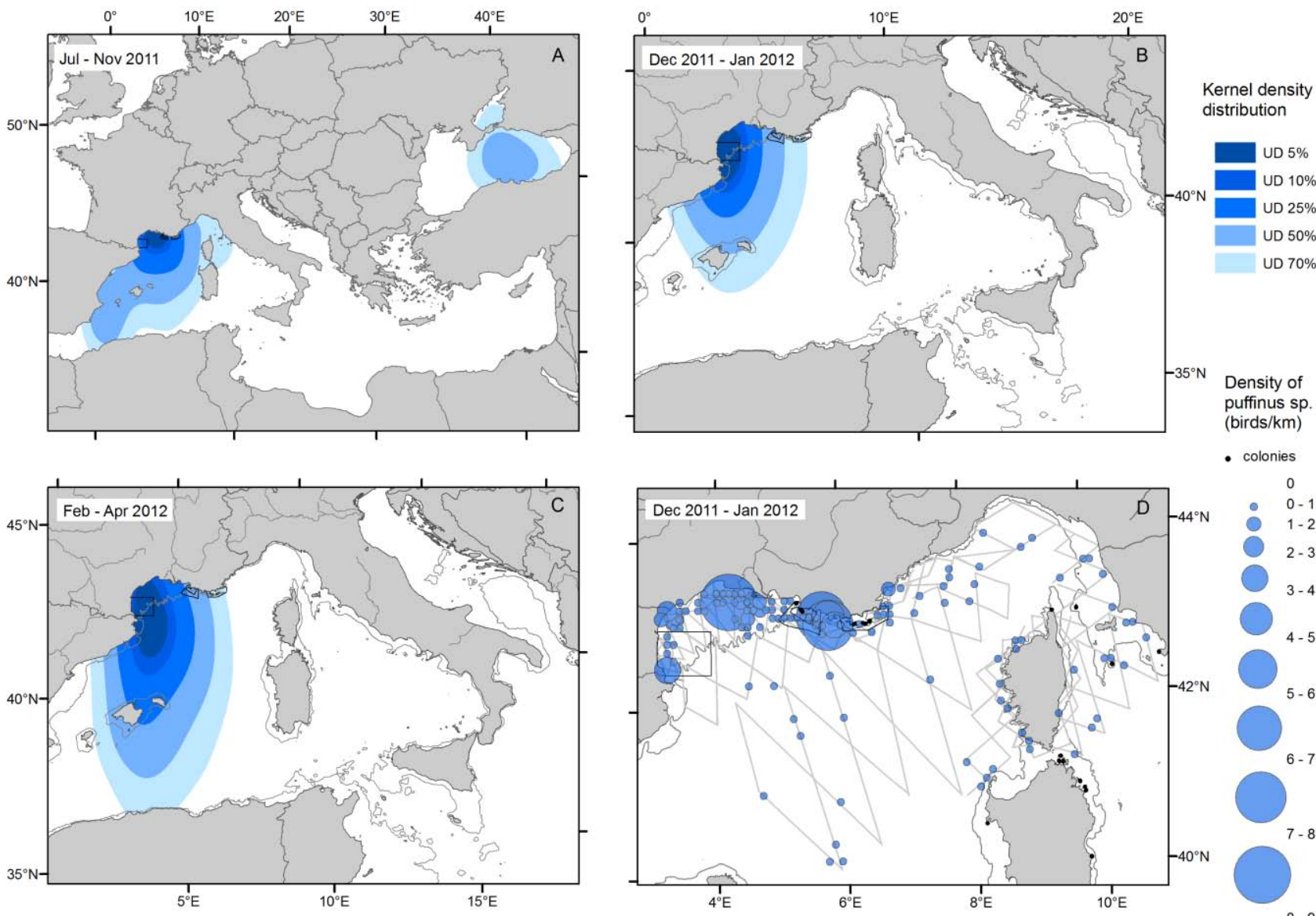

- colonies

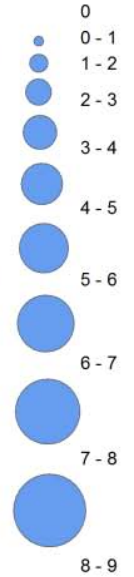


Figure 6: Tukey plot of weekly variations in yelkouan shearwaters activity (percentage of time spent on water), derived from wet/dry recorder of GLS. The number of individuals included in the weekly calculation is noted above each bar.

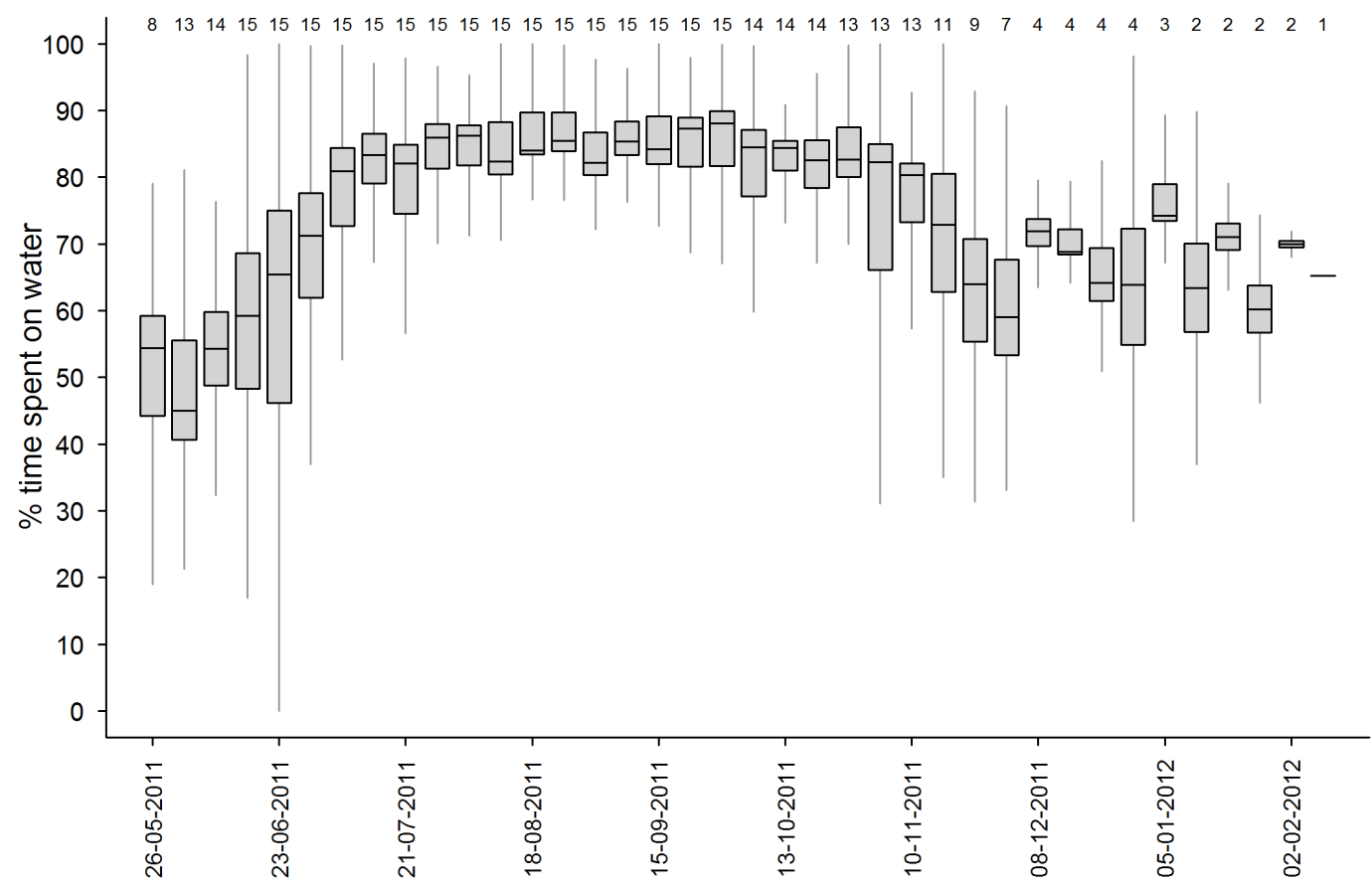

Figure 7: Stable isotopes signatures of yelkouan shearwaters (filled symbols correspond to the average value \pm SD) during the non-breeding period (July-October) in 2010-2011 (A; $\mathrm{n}=37$ individuals) and 2011-2012 $(\mathrm{B} ; \mathrm{n}=33$ individuals). Groups were inferred using a hierarchical cluster analysis on the $\delta 13 \mathrm{C}$ isotopic values of the primary feathers. Isotopic signatures of individuals tracked with GLS are colour-marked according to their non-breeding foraging grounds (red: Black Sea, light blue: Mediterranean Sea). Isotopic values for shearwaters potential prey: pelagic fish (Bănaru D, data) and krill are represented with grey symbols (hexagone and star for fish and krill respectively). Isotopic values for the krill (Meganycthiphanes norvegica) are from [Cardona et al. 2012] and [Papiol et al. 2013].
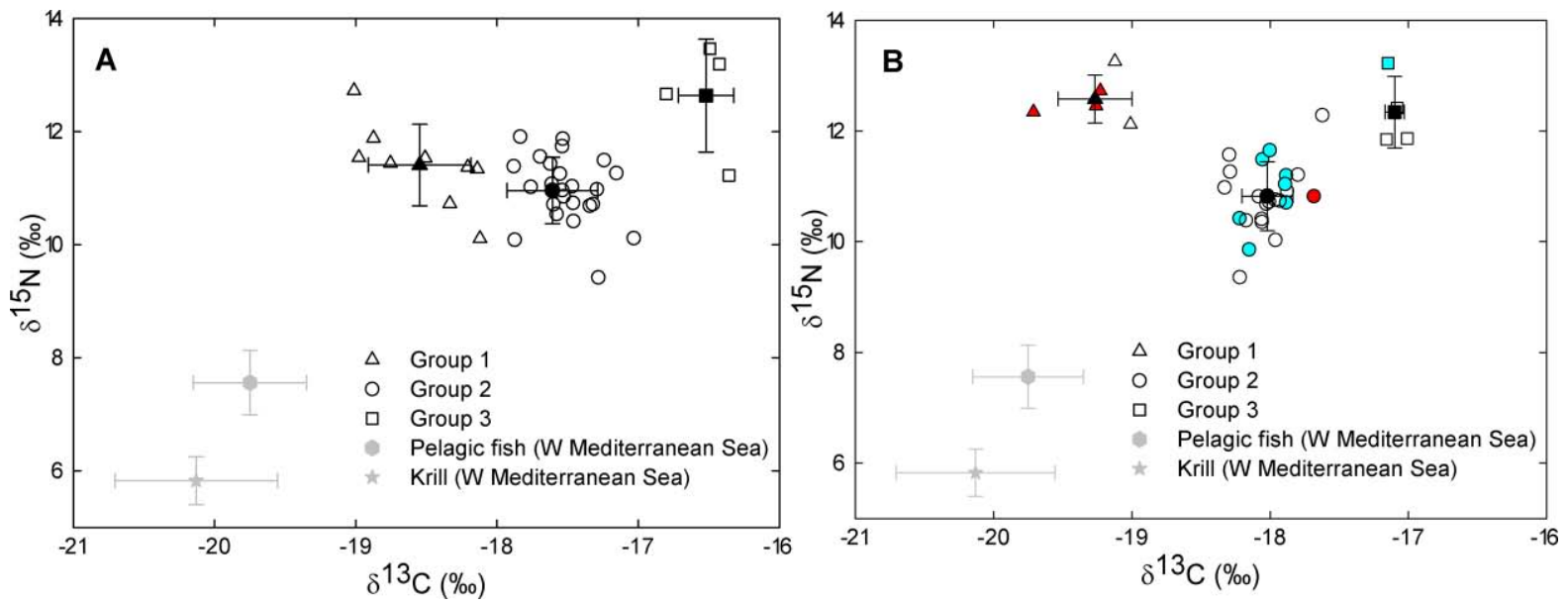